\title{
Development of micro soap bubble generator for PIV tracer using home stereolithography 3D printer
}

\author{
Shu Shibata ${ }^{1}$, Takumi Yamazaki ${ }^{2}$ and Hisashi Matsuda ${ }^{3 *}$ \\ ${ }^{1}$ Undergraduate Student, Hokkaido University of Science \\ (Currently, Mitsubishi Materials Techno Co.), Japan \\ ${ }^{2}$ Undergraduate Student, Hokkaido University of Science \\ (Currently, Toshiba Elevator and Building Systems Corp.), Japan \\ ${ }^{3}$ Hokkaido University of Science, Department of Mechanical Engineering, Sapporo, Japan. \\ *matsuda-h@hus.ac.jp
}

\begin{abstract}
A micro soap bubble generator for tracers for PIV measurement was developed using a home stereolithography 3D printer. The nozzle has a coaxial triple pipe structure, and an orifice cap is attached to the nozzle head. The inner diameter of the central pipe is $0.7 \mathrm{~mm}$, and the wall thickness of the central pipe is $0.7 \mathrm{~mm}$. From the comparison of the smoke wire visualization result of the flow around the cylinder placed under the mainstream flow velocity of $3 \mathrm{~m} / \mathrm{s}$ and the PIV measurement result, it was confirmed that the generated micro soap bubbles have good followability to the flow. Generated bubbles' particle size was estimated to be $\Phi 0.2 \mathrm{~mm}$ at the minimum and $\Phi 6.3 \mathrm{~mm}$ at the maximum. The most common was $\Phi 0.9 \mathrm{~mm} \pm 0.1$ $\mathrm{mm}$, accounting for more than $50 \%$ of the total.
\end{abstract}

\section{Introduction}

Smoke particles are often used as tracers for PIV measurement. However, if the light source's output is insufficient, the brightness of the particle image obtained by visualization will be inadequate due to inadequate light scattering from smoke particles. As a solution to this problem, a method to increase the image brightness by changing the scattered light intensity of the tracer particles without changing the light's output is conceivable. Caridi (2018) reported that, using helium-filled soap bubbles (HFSB) as tracer particles, high reflection about 10,000 times more than smoke particles such as 2-Ethylhexyl and DSHE is obtained. As the intensity of light increases, it becomes possible to measure in a large-scale flow field as large as several meters. Bosbach et al. (2009) performed PIV measurement of the convection flow field inside the aircraft cabin using HFSB and obtained important knowledge about cabin ventilation. The particle size of smoke particles is about $1 \mu \mathrm{m}$; it can be considered that the followability to the airflow is satisfactory, on the other hand when a large particle such as HFSB is used as a tracer, the slip speed (difference between flow velocity and particle velocity used) increases and brings mis-followability (Cao et al., 2014). For this reason, Scarano et al. (2015) have developed an excellent HFSB generation system. They conducted a survey on the followability of systematic tracer particles for the flow around a cylinder to optimize it. Performing tomographic PIV measurement of the wake of a cylinder showed that HFSB with well-controlled particle size and buoyancy enables highly accurate turbulence measurement. Flaleiros et al. (2019) used two types of bubble generators such as a pitot tube type and an orifice type, for comparison. By changing the supply amount of air, BFS (the bubble fluid solution), and helium gas, the bubble generation form and the effect on the soap bubble diameter were systematically investigated. They quantitatively clarified the flow condition of making the helium-filled microbubbles with neutral buoyancy. 
In addition, Barros et al. (2019) clarified the details of complex wake by 3D PIV measurement for the flow around the sphere using micro air-bubbles of 10 to $30 \mu \mathrm{m}$ as a tracer. The development of a generator capable of releasing a large amount of HFSB for wind tunnel experiments has also been reported by Gibeau \& Ghaemi (2018). The Bubble generator developed by Scarano et al. has been commercialized (Kanomax Inc.); however, it is not easy to introduce from cost.

If the micro soap bubble generator can be manufactured using a home 3D printer that has become widespread in recent years, the cost required for PIV measurement can be significantly reduced. In this study, we attempted to manufacture a micro soap bubble generator nozzle using a home hot-melt 3D printer and a stereolithography 3D printer. The purpose is to realize a low-cost PIV measurement system by developing a micro soap bubble generator.

\section{Development of nozzle for generating micro soap bubble}

\subsection{Nozzle production using a hot-melt 3D printer}

As reported by Bosback et al. (2006) and Faleiros et al. (2019), the coaxial triple pipe structure is important for generating microbubbles. We understood that the key point is the mechanism that generates microbubbles in the inner double pipe part and separates the microbubbles one by one by sending air from the outermost pipe. In Faleiros et al. (2019), both a pitot tube type and an orifice type nozzle were studied. It is difficult to accurately manufacture the pitot tube type nozzle with a home 3D printer. In addition, since it is impossible to check the manufacturing status even if the entire nozzle is integrated, we decided to adopt the Bosback method (Bosback et al. 2006), which combines an orifice cap with a coaxial triple pipe. Following Faleiros et al. (2019), we aimed to generate microbubbles with a diameter of $0.6 \mathrm{~mm}$.

For making the nozzle, we decided to use a hot-melt 3D printer (Creality Ender 3 pro, Creality Co.), which has become popular in recent years. A PLA resin made by Creality was used as the filament for the printer. Cura 15.04 was used as the slicer software. The minimum stacking pitch of this printer is $0.1 \mathrm{~mm}$. Fig.1 shows the hot-melt 3D printer used, and Table 1 shows the specifications of the printer. Bosback et al. (2006) and Faleiros et al. (2019) have reported schematic cross-sectional views of the microbubble generator. However detailed dimensions such as pipe wall thickness have not been clarified. Therefore, as the first attempt, we decided to manufacture a coaxial triple pipe structure as shown in Fig. 2. The design concept is to provide a central pipe for helium supply, stack a BFS pipe on the outside, and form an air pipe for separating the microbubbles on the outside. The helium supply is provided from the nozzle end, and the BFS and air supply are provided at the mid portion of the nozzle. First, we checked whether printing with the hot-melt 3D printer was possible for this coaxial triple pipe structure. A total of 12 nozzles were prototyped while changing the overall and detailed dimensions of the nozzle, and the bubble generation rate of each nozzle was tested. As the bubble fluid solution (BFS), a mixed solution of $30 \%$ water, $40 \%$ polyvinyl alcohol, and 30\% CuCute (Kao Corp.) was used. Micro-compressors for fish raising were used to generate soap bubbles.

Aiming to generate micro soap bubbles with a diameter of $0.6 \mathrm{~mm}$, we tried to reduce the diameter of the innermost central pipe as much as possible. We repeated trial production until the pipe with an inner diameter of $1 \mathrm{~mm}$ was formed without clogging. When we finally conducted a micro bubble generation test using the completed prototype nozzle, we could generate micro soap bubbles continuously for 16 seconds, albeit only once. Fig. 3 shows the state during operation. Although the orifice cap was not attached, the validity of the triple coaxial structure was verified.

However, it is difficult to reduce the thickness of the nozzle wall surface to less than $1 \mathrm{~mm}$ with the hotmelt 3D printer used in this study. In addition, it became clear that the reproducibility of production was low, and the yield was poor. Fig. 4 shows examples of failure. It turned out that there is a big problem in manufacturing accuracy in each case. 


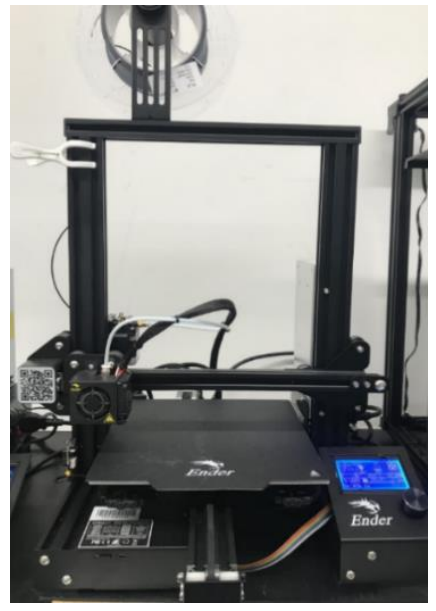

Table 1 Specifications of the fused deposition modeling 3D printer

\begin{tabular}{|l|c|}
\hline Print range $[\mathrm{mm}]$ & $220 \times 220 \times 250$ \\
\hline Nozzle diameter $[\mathrm{mm}]$ & 0.4 \\
\hline Printing accuracy $[\mathrm{mm}]$ & \pm 0.1 \\
\hline Maximum printing speed $[\mathrm{mm} / \mathrm{s}]$ & 180 \\
\hline Stacking pitch $[\mathrm{mm}]$ & $0.1 \sim 0.4$ \\
\hline Supported filament $[\mathrm{mm}]$ & 1.75 \\
\hline
\end{tabular}

Fig.1 Fused deposition modeling 3D printer

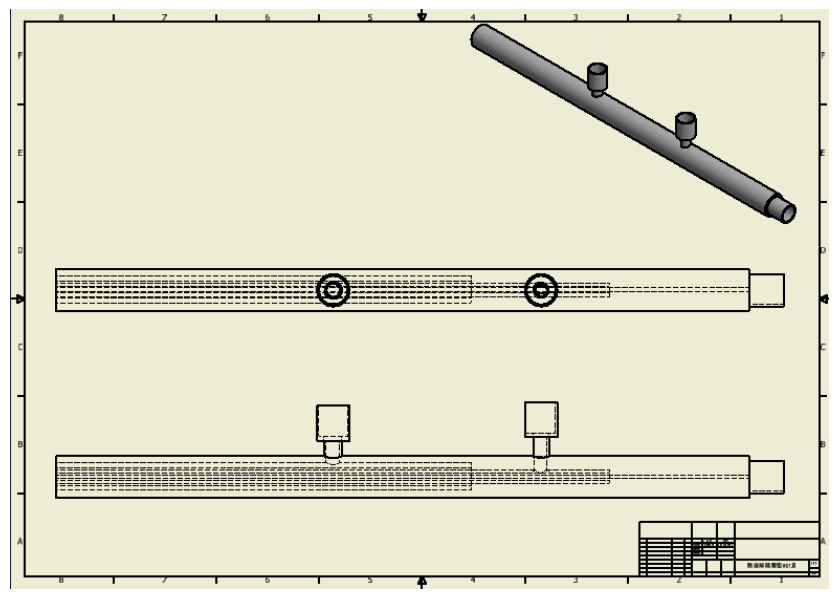

Fig. 2 Nozzle for generating microbubbles for trial production

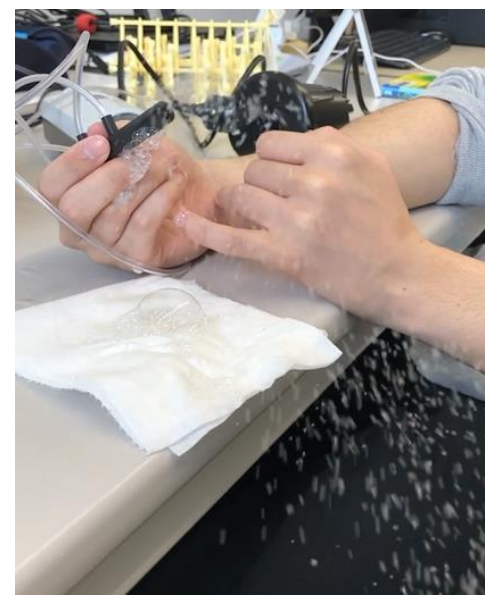

Fig. 3 State of micro soap bubbles generation by prototype nozzle

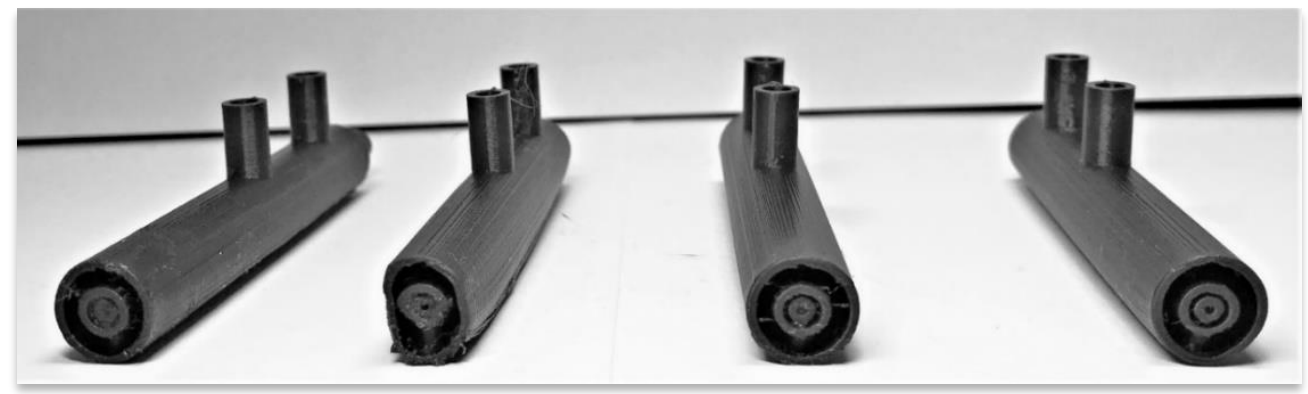

Fig. 4 Examples of nozzle manufacturing failure using a hot-melt 3D printer 


\subsection{Quality function deployment}

The micro soap bubbles were successfully generated, although it was only once, we decided to sort out the knowledge about nozzle design so far using QFD (Quality function deployment). QFD is an effective tool for associating the quality required for the development target with technical characteristics. As orifice type coaxial triple pipe nozzle design variables, the central pipe diameter, the BFS pipe diameter, the air pipe diameter, the pipe length, the central pipe wall thickness, the BFS pipe wall thickness, the air pipe wall thickness, the nozzle cap diameter, and the nozzle cap thickness and the nozzle cap corner $\mathrm{R}$ were selected. As the requirements for a micro soap bubbles generator for these design variables, the required dimensional feasibility, pore depth processing accuracy, soap bubble feasibility, and wet edge area, were mentioned. The degree of influence on these requirements was evaluated from the findings obtained in the prototypes so far. As a result, four items, the central pipe diameter, and the BFS pipe diameter, the central pipe wall thickness, and the BFS pipe wall thickness, were extracted as important design variables. Table 2 shows an excerpt of the QFD results.

Table 2 QFD results

\begin{tabular}{|c|c|c|c|c|c|c|c|}
\hline & importance & Фhe & ФBFS & Фair & $t_{\text {he }}$ & $t_{\text {BFS }}$ & BFS \\
\hline Feasibility of requirements system & 5 & 9 & 9 & 1 & 9 & 9 & \\
\hline Depth accuracy & 5 & 9 & 9 & 9 & 3 & & \\
\hline Soap bubble feasibility & 5 & 9 & 9 & & 9 & 9 & 9 \\
\hline Wet edge area & 3 & 3 & 3 & & 9 & 9 & 9 \\
\hline & & 144 & 144 & 50 & 132 & 117 & 72 \\
\hline
\end{tabular}

\subsection{Nozzle production using a stereolithography 3D printer}

Since it was found that the hot-melt 3D printer could not solve the problem of manufacturing accuracy, we decided to introduce a stereolithography 3D printer (NOVA3D BENE4 MONO) to improve the modeling accuracy of the design variables extracted by QFD. The minimum stacking pitch of this printer is $0.05 \mathrm{~mm}$, and higher accuracy can be expected compared to the hot-melt type. The resin used was standard photopolymer resin (semi-transparent) manufactured by ELEGOO. The slicer software used was NovaMaker. Fig.5 shows the appearance of BENE4, and Table 3 shows the specifications of BENE4. Depending on the placement direction of the model with respect to the platform, the finish accuracy of the modeled object will differ. Since horizontal and diagonal placements are affected by gravity during molding, vertical placement was adopted. It was also found that the coaxial pipe size of the nozzle was increased by about $10 \%$ with respect to the design value. The influence of the platform position during molding was also investigated, and it was confirmed that the central part was suitable. We also investigated how thin a wall surface can be formed. It was confirmed that up to $0.2 \mathrm{~mm}$ of the partition wall can be modeled as a cylinder. We clarified the molding up to a pipe diameter of $0.6 \mathrm{~mm}$ to a depth of about $60 \mathrm{~mm}$. The stacking pitch was set to $0.5 \mathrm{~mm}$. The exposure time set to $3 \mathrm{~s}$.

Under the above processing conditions, we pursued the smallest possible hole diameter for the central pipe diameter while having high reproducibility. We searched for a wall thickness that enables stable molding of a central pipe with a length of $65 \mathrm{~mm}$ without cracking. As a result, a wall thickness of $0.7 \mathrm{~mm}$ was adopted. We also pursued the best shape by trial and error for the BFS pipe diameter and the BFS pipe wall thickness. After 60 prototypes, we succeeded in developing a nozzle that stably generates micro soap bubbles. The total length of the nozzle was $66 \mathrm{~mm}$. The structure is such that the supply part of the central pipe is provided at the nozzle end, and the BFS liquid supply part and the blowout air supply part are 
provided on the side surface of the intermediate part of the nozzle. The production time with the 3D printer is about 3 hours. Fig. 6 shows the overall view of the completed final nozzle, and Fig.7 shows the state when soap bubbles are generated (without the orifice cap). As for the orifice cap, since the coaxial triple pipe nozzle is not molded with the dimensions according to the design drawing, it is molded about $10 \%$ larger, so it was necessary to fine-tune the inner diameter while observing the quality of the nozzle. Fig. 8 shows a detailed cross-sectional view of the completed orifice cap and the completed nozzle.

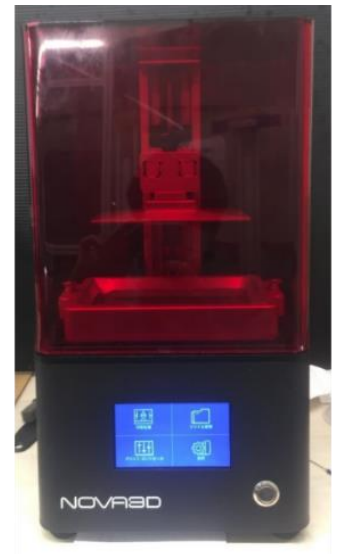

Fig.5 Stereolithography 3D printer
Table 3 Specifications of the stereolithography $3 \mathrm{D}$ printer

\begin{tabular}{|l|c|}
\hline Print range $[\mathrm{mm}]$ & $130 \times 70 \times 150$ \\
\hline Printing accuracy $[\mu \mathrm{m}]$ & $50 \times 50$ \\
\hline Printing speed $[\mathrm{mm} / \mathrm{h}]$ & $10 \sim 30$ \\
\hline Stacking pitch $[\mathrm{mm}]$ & 0.05 \\
\hline
\end{tabular}

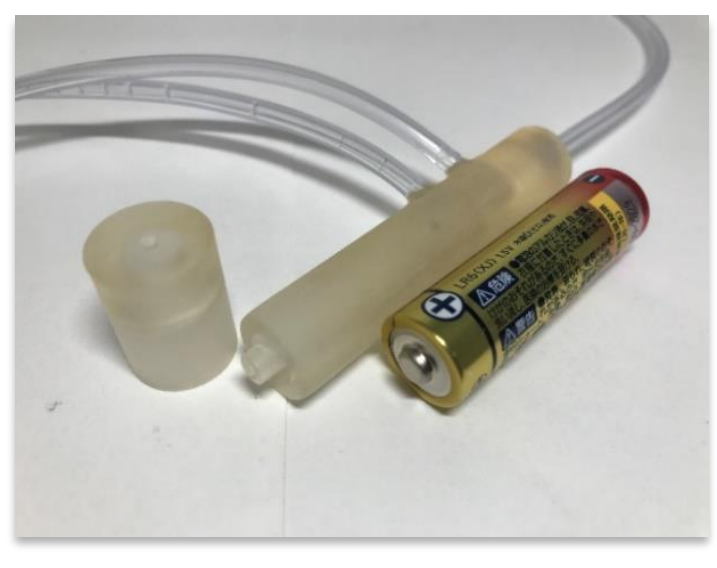

Fig.6 Complete nozzle

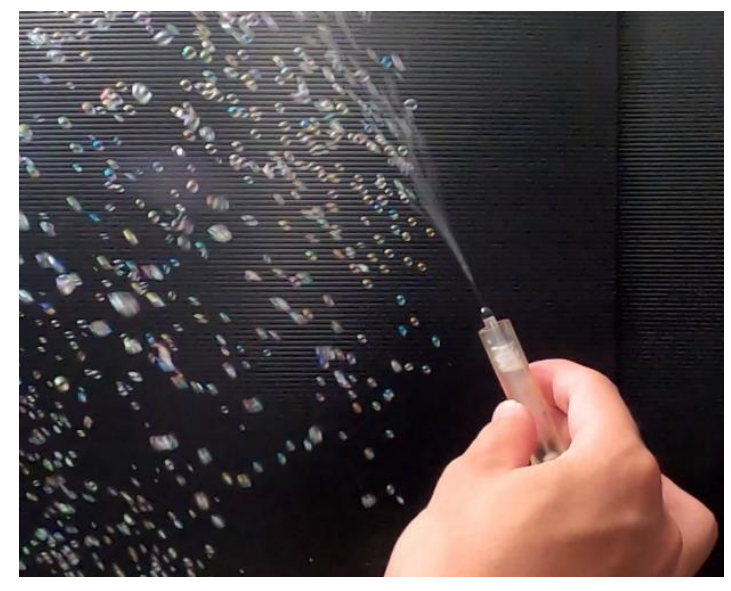

Fig.7 State during operation 


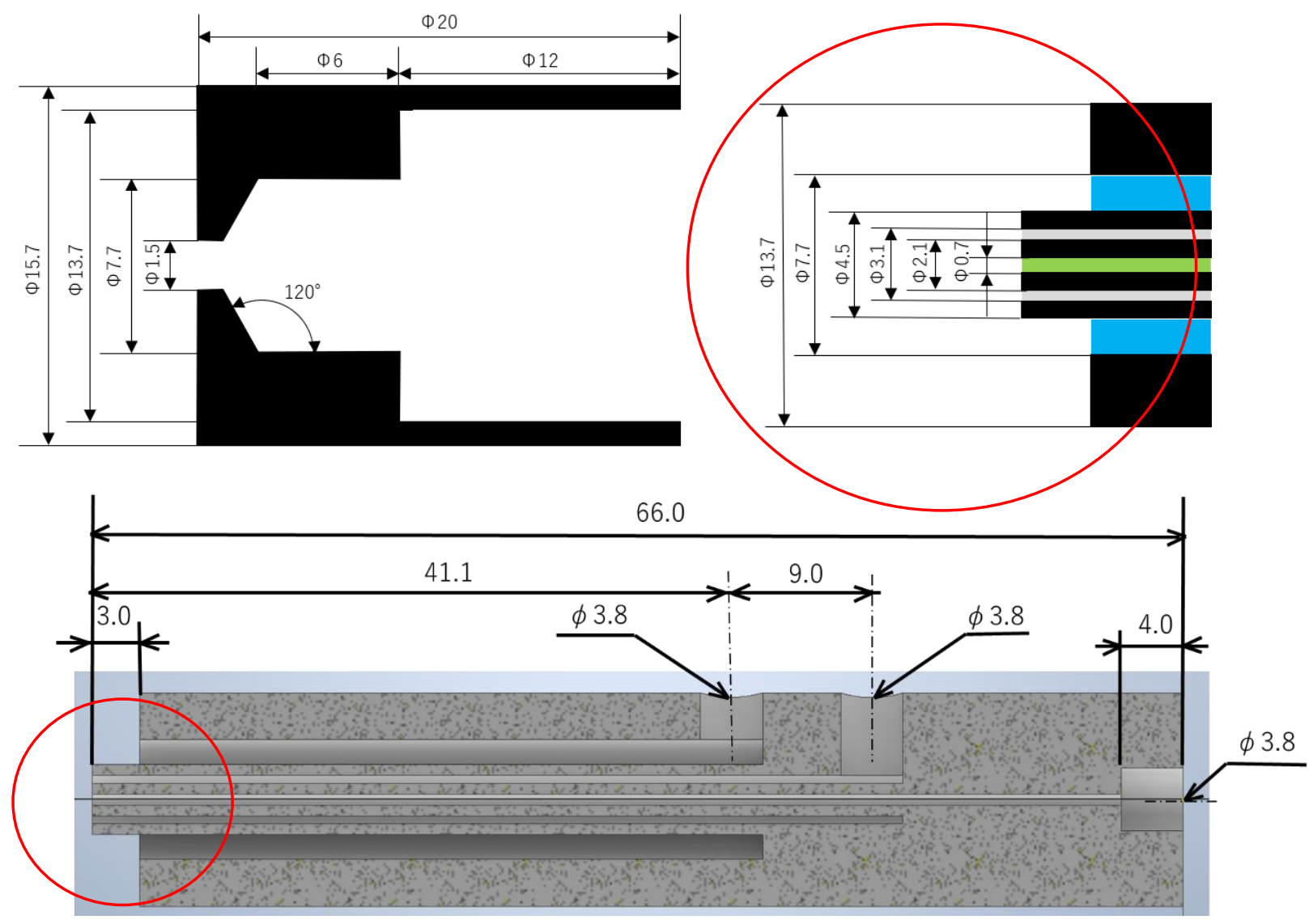

Fig. 8 Detailed cross-sectional view of the complete orifice cap and nozzle

Next, the suitable conditions for generating micro soap bubbles were adjusted under the condition that air was also supplied to the central pipe. The most stable conditions for generating microbubbles were 4.35 $\mathrm{ml} / \mathrm{min}, 0.50 \mathrm{ml} / \mathrm{min}$, and $0.45 \mathrm{ml} / \mathrm{min}$, respectively, as the supply air, BFS, and helium alternative airflow rates. The flowmeters used for adjustment are PFM710 (SMC Corporation), LM05ZZT-AR (HORIBA, Ltd.), and mass flow meter MODEL 3810DSII (Koflock Co., Ltd.). The air compressor used was SK-11 SR-045 (Fujiwara Sangyo Co., Ltd.). Fig.9 shows a configuration of the soap bubble generator developed. The total cost (including the cost of the stereolithography $3 \mathrm{D}$ printer) for constructing this system was about 1,400 dollars.

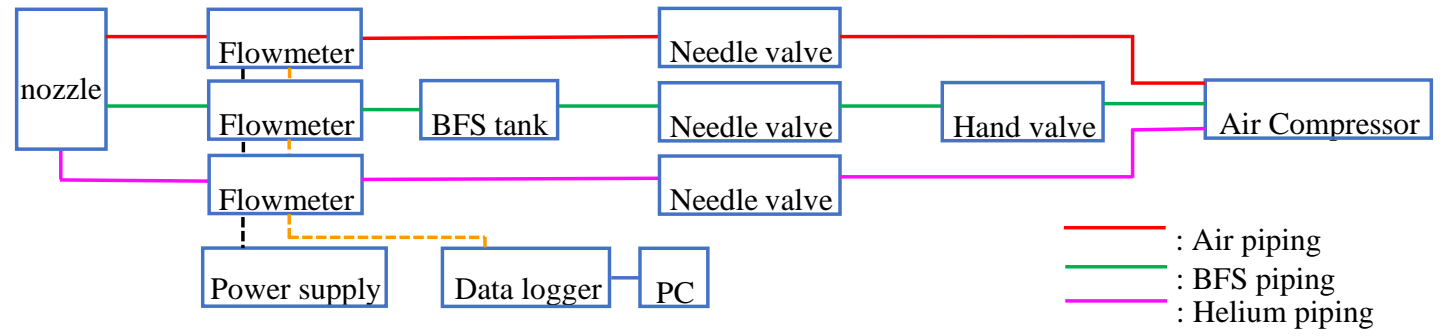

Fig.9 Overview of the micro soap bubble generator 


\section{Property test of the micro soap bubble generator}

Following the research by Scarano et al. (2018), the followability of the micro soap bubbles was evaluated for the flow around the cylinder. A cylinder (outer diameter $114 \mathrm{~mm}$ ) was placed in a circulating wind tunnel (maximum wind speed: $25 \mathrm{~m} / \mathrm{s}$, Ebara Corporation) of an outlet of $400 \mathrm{~mm} \times 400 \mathrm{~mm}$. Under the mainstream velocity of $U=3 \mathrm{~m} / \mathrm{s}$, the symmetry of the flow was checked using the smoke wire method. Fig. 10 shows the experimental scene, and Fig.11 shows the visualization result by the smoke wire method. Liquid paraffin was used as the smoke material.

Next, using a high-speed camera of K7-USB (Kato Koken Co., Ltd.) and the analysis software of FLOW EXPERT 2D2C-L (Kato Koken Co., Ltd.), PTV/PIV measurements were carried out. In this measurement, the air was supplied to the central pipe instead of helium gas. For the experiment, adjustable focus blue laser (2.5W, Chinanczone) for the light source, CCM5-P01/M (Solab Japan Co., Ltd.) for the optical mirror, LK1684L1-A (Solab Japan Co., Ltd.) for the cylindrical lens were used. Fig.12 shows the trace lines of micro soap bubbles from PTV measurements, and Fig.13 shows the same data PIV-processed by the correlation method. From the PIV measurement results, good symmetry was observed, as in the case obtained by the smoke wire method. It was confirmed that the micro soap bubbles generated from the developed nozzle had good followability.

To find out what size soap bubbles were generated, we selected a total of 271 particles that could be clearly observed from 20 snapshots obtained during the measurement. The contours of the soap bubbles were photographed, and the actual diameter of the soap bubbles was estimated based on the angle of view and the number of pixels at the time of photography. An example of the snapshot image is shown in Fig.14. A histogram of the measurement data is shown in Fig.15. The minimum and maximum diameters of the micro soap bubbles generated by the newly developed nozzle were estimated to be about $0.2 \mathrm{~mm}$ and 6.3 $\mathrm{mm}$, respectively. The most frequently generated particle diameter was $0.9 \mathrm{~mm} \pm 0.1 \mathrm{~mm}$, and the generation rate was about $50 \%$ of the total. Although it was larger than our target of $\Phi 0.6 \mathrm{~mm}$, we coould generate soap bubbles of $\Phi 1 \mathrm{~mm}$ or less stably.

The equation of motion in the vertical direction of a particle is obtained as in eq. (1). Here, $m$ is the mass of the particle, $u_{p}$ is the velocity of the particle, $u_{f}$ is the velocity of airflow, $d$ is the diameter of the particle, $\rho_{\mathrm{p}}$ is the density of the particle, $\rho_{\mathrm{f}}$ is the density of air, and $\mathrm{g}$ is the acceleration of gravity (Saito and Nakajima, 2017).

$$
m \frac{d u_{p}}{d_{t}}=\frac{\pi d^{3}}{6} \rho_{p} g-\frac{\pi d^{3}}{6} \rho_{f} g-3 \pi \mu d\left(u_{p}-u_{f}\right) \ldots \ldots
$$

Here, the mass $m$ of the particles is obtained by multiplying the particle diameter by the film thickness in soap bubbles. The film thickness $\Delta \mathrm{t}$ is assumed to be about $0.1 \mu \mathrm{m}$ according to the literature (Faleiros et al., 2019). The sedimentation velocity of the soap bubbles is calculated as (2).

$$
u_{t}=u_{p}-u_{f}=\frac{\left(\Delta t \rho_{p}-\rho_{f}\right) d^{2} g}{18 \mu} \ldots \ldots
$$

The most frequently occurring soap bubble with a diameter of $0.9 \mathrm{~mm}$ has a settling velocity of $0.029 \mathrm{~m} / \mathrm{s}$, and the settling distance, when measured at $1000 \mathrm{FPS}(0.001 \mathrm{~s})$, is $0.03 \mathrm{~mm}$. It can be judged that they had good followability. 




Fig.10 Smoke wire visualization experiment

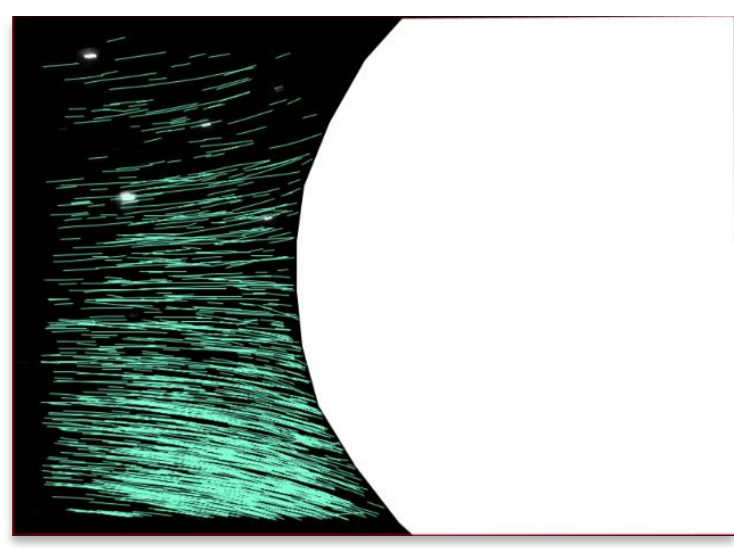

Fig. 12 PTV analysis results

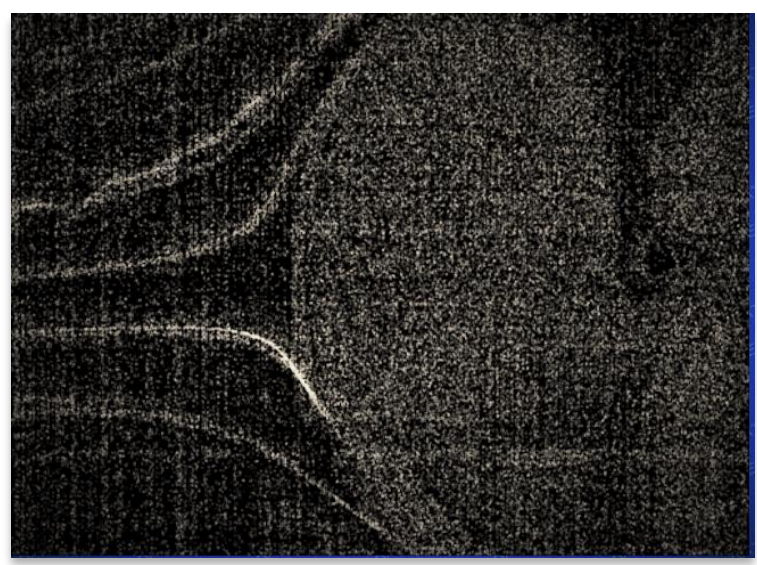

Fig.11 Smoke wire visualization

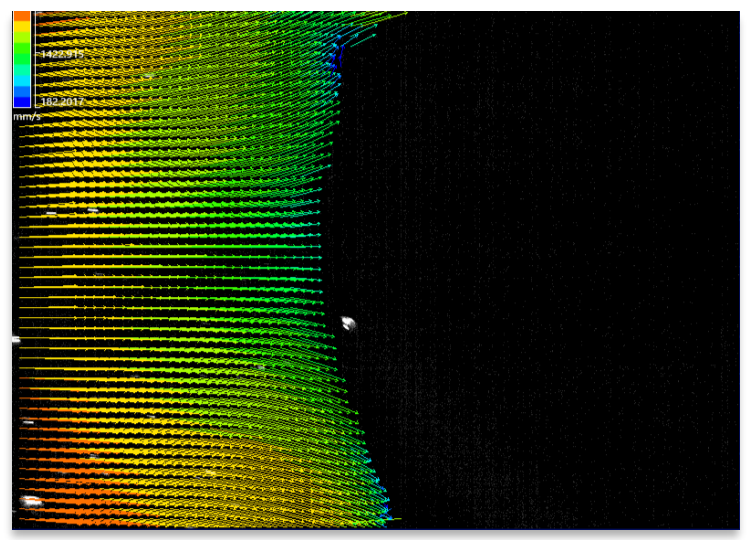

Fig. 13 PIV analysis results

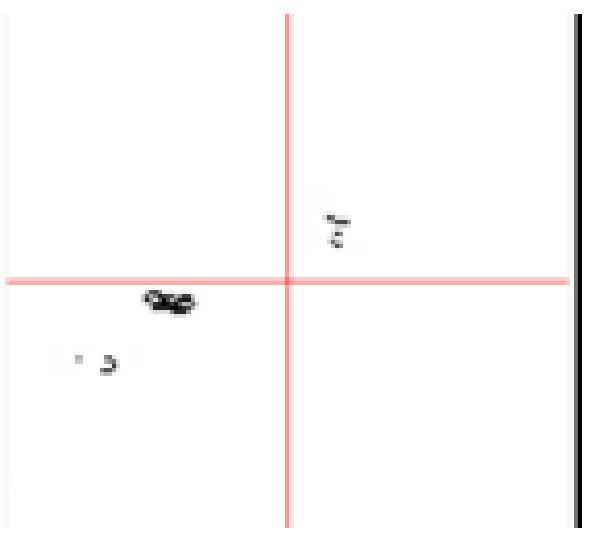

Fig.14 Snapshot of micro soap bubbles



Fig. 15 Histgram of diameter of micro soap bubbles 


\section{Wind tunnel test using micro soap bubbles as a tracer}

Finally, PIV measurement was attempted by applying the developed micro soap bubbles tracer to a wind tunnel experiment for a two-dimensional backstep (step height $20 \mathrm{~mm}$ ) flow. Fig. 16 shows the state during PIV measurement. Fig. 17 shows the PIV measurement results at the mainstream wind speed $U=5 \mathrm{~m} / \mathrm{s}$. The flow is from left to right in the figure. It was confirmed that the wind speed obtained from the PIV measurement results was in good agreement with the wind speed measurement results by the hotwire anemometer. Good measurement was confirmed even at mainstream speed $\mathrm{U}=20 \mathrm{~m} / \mathrm{s}$.

The PIV measurement for the flow around the NACA0015 (U=5m/s) blade of the chord length of 300 $\mathrm{mm}$ in an environment of $-5^{\circ} \mathrm{C}$ was also carried out using the natural snow wind tunnel Hokkaido University of Science (Matsuda et al., 2021). Fig. 18 shows the state of the wind tunnel experiment. Vision Research Inc.'s Phantom V1212 was used for the high-speed camera, and Kato Koken's 8W laser sheet was used for the laser light source. FLOW EXPERT 2D2C-L (Kato Koken Co., Ltd.) was also used as the measurement software. In Fig.19, the flow is from left to right. It was possible to observe large-scale separation from the leading edge of the blade, similar to the smoke visualization result. The BFS did not freeze even in a measurement environment of $-5^{\circ} \mathrm{C}$, and that the micro soap bubbles after generation also maintained good followability. It was found that the newly developed micro soap bubble generator is extremely effective for PIV measurement under various conditions.

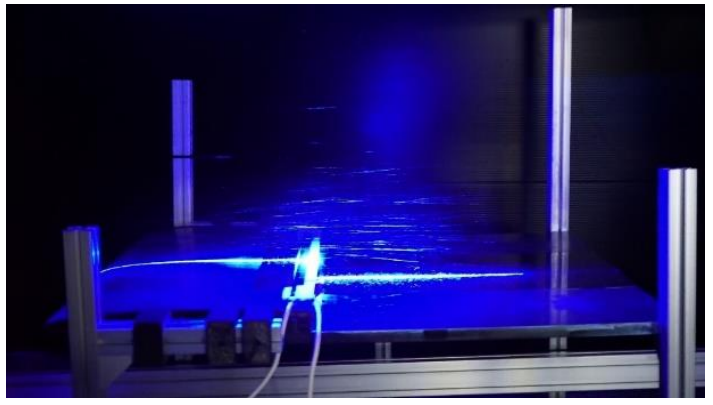

Fig.16 PIV measurement of 2D backstep model

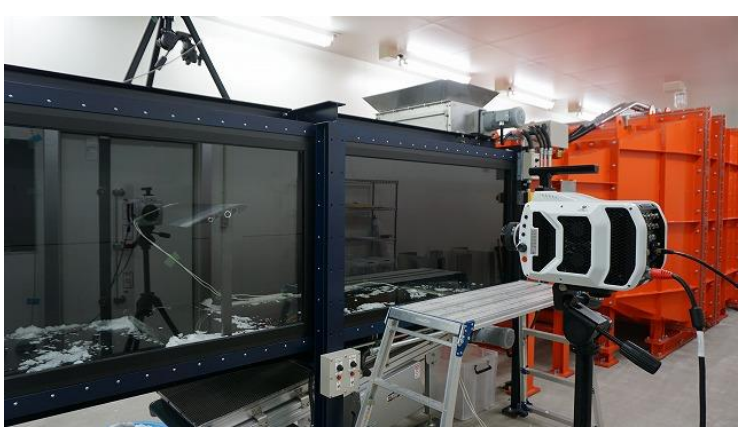

Fig.18 Natural snow wind tunnel facility of the Hokkaido University Science

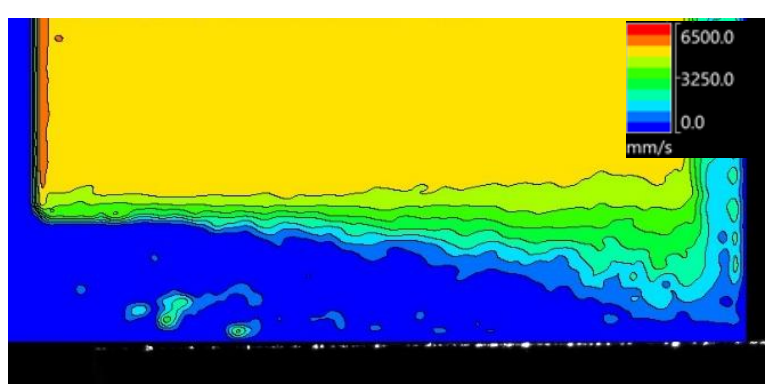

Fig.17 PIV analysis result $(\mathrm{U}=5 \mathrm{~m} / \mathrm{s})$

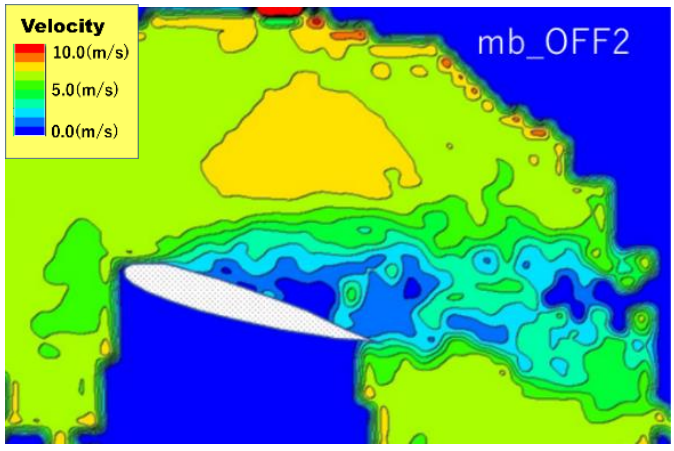

Fig.19 PIV analysis result $(\mathrm{U}=5 \mathrm{~m} / \mathrm{s})$ 


\section{Conclusion}

A micro soap bubble generator for tracers of PIV measurement was developed using a home stereolithography 3D printer. The nozzle for generating micro soap bubbles has a coaxial triple pipe structure, and an orifice cap is attached to the nozzle head. The inner diameter of the central pipe of the nozzle for generating is $0.7 \mathrm{~mm}$, and the wall thickness of the central pipe is $0.7 \mathrm{~mm}$. A detailed crosssection of the entire nozzle was shown. It took about 3 hours to print one nozzle. From the comparison of the smoke wire visualization result of the flow around the cylinder and the PIV measurement result, it was confirmed that the generated micro soap bubbles have good followability to the steady flow field. The particle size of the generated bubbles was estimated to be $0.2 \mathrm{~mm}$ at the minimum and $6.3 \mathrm{~mm}$ at the maximum. The most common occurrence was $0.9 \mathrm{~mm} \pm 0.1 \mathrm{~mm}$, which was about $50 \%$ or more of the total. Applying the developed micro soap bubbles generator as a seeding device, a two-dimensional backstep flow and the flow around the blade were evaluated. It was found that the newly developed micro soap bubble generator is extremely effective for PIV measurement under various conditions. This investigation was started as graduation research; we will proceed with the research toward the generation of micro soap bubbles that can cope with field PIV measurement in the future.

\section{Acknowledgments}

This research started with the kind advice of Prof. Scarano (TU Delft). For the particle size study, we were advised by Associate Professor Tasaka of Hokkaido University. Wind tunnel experiments were helped by Mr. Toshiki Takahashi and Mr. Tasuku Tanaka (4th years student of the Hokkaido University of Science at that time). We would like to thank all the people involved for their kindness.

\section{References}

Barros, D., Duan, Y., Troolin, D., Longmire, E.K. and Lai, W. (2019), Soap bubbles for volumetric velocity measurements in air flows, $13^{\text {th }}$ ISPIV 2019, Munich, Germany.

Bosbach, J., Kühn, M. and Wagner, C. (2009), Large- scale particle image velocimetry with helium filled soap bubbles. Exp Fluids 46:539-547, DOI 10;1007/s00348-008-0579-0.

Cao X., Liu J. and Jiang N. (2014), Particle image velocimetry measurement of indoor airflow field : A review of the technologies and applications, Energy and Buildings, DOI:10.1016/J.enbuild.2013.11.012

Caridi, G.C.A. (2018), Development and application of helium-filled soap bubbles for large-scale PIV experiments in aerodynamics. Ph.D. thesis, doi.org/10.4233/uuid:effc65f6-34df-4eac-8ad9$3 f d b 22 a 294 d c$.

Fleiros, D.E., Tuinstra, M., Sciacchitano, A. and Scarano, F. (2019), Generation and control of helium-filled soap bubbles for PIV, Exp Fluids 60:40, doi.org/10.1007/s00348-019-2687-4.

Gibeau, B. and Ghaemi, S. (2018), A modular, 3D-printed helium-filled soap bubble generator for largescale volumetric flow measurements, Exp Fluids 59:178, doi.org/10.1007/s00348-018-2634-9.

Matsuda, H., Chiba, T., Yagami, M., Tajima, Y., Watanabe, N., Sato, H. and Takeyama, M. (2021), Control of snow falling flow around NACA0015 blade using practical-use Plasma electrode, Asian Conference of Gas Turbine 2021, Quingdao, Chaina, (Scheduled to be presented)

Saito, Y. and Nakajima, R., (2017), Visualization of Inner Flow inside Air Conditioning System with PIV, Calsonic Kansei Technical Review Vol.13 p22 26 (in Japanese).

Scarano, F., Ghaemi, S., Cardi, G.C.A., Bosback, J., Dierksheide, U. and Sciacchitano, A. (2015), On the use of helium-filled soap bubbles for large-scale tomographic PIV in wind tunnel experiments, Exp Fluids 56:42, DOI 10.1007/s00348-015-1909-7. 